\title{
Analisis Penerapan MRP Terhadap Perencanaan Dan Pengendalian Persediaan Bahan Baku Pada PT. Latif Di Kediri
}

\author{
Gunawan Wibisono $^{(1)}$, Sri Rahayuningsih ${ }^{(2)}$ Heribertus Budi Santoso ${ }^{(3)}$ \\ ${ }^{(1,2,3)}$ Jurusan Teknik Industri, Fakultas Teknik, Universitas Kadiri \\ Email: gunawanwibi95@gmail.com ${ }^{(1)}$
}

\begin{abstract}
Abstrak
PT. Latif merupakan industri yang bergerak dalam bidang furniture rotan sintetis, yang salah satu produk terlaris adalah SH-15. Masalah dalam penelitian ini mengenai persediaan bahan baku dengan menggunakan sistem made in order. Oleh karena itu dibutuhkan suatu sistem informasi yang diharapkan dalam pemenuhan kebutuhan bahan baku dapat dilakukan dengan tepat dan penentuan biaya persediaannya dapat ditetapkan seoptimal mungkin yaitu melalui penerapan MRP. Variabel penelitian dalam hal ini adalah perencanaan persediaan bahan baku. MRP diawali dengan melakukan peramalan akan jumlah permintaan/ produksi untuk waktu yang akan datang. Peramalan ini dilakukan dengan menggunakan metode Moving Average $\mathrm{N}=$ 1, dan Single Exponential Smoothing $=0.8$. Lalu ditentukan nilai terkecil dari SEE, MAD, dan MAPE dari masing-masing metode. Setelah terpilih salah satu metode terbaik maka metode tersebut akan dijadikan landasan untuk meramalkan jumlah kebutuhan permintaan selama satu tahun kedepan. Perbandingan antara biaya persediaan minimum metode Lot for Lot sebesar Rp.60.000 dan Part periode Balancing sebesar Rp. 44.733.750,-. Dari hasil penghitungan kedua lot sizing dapat diambil kesimpulan bahwa penerapan metode Lot Sizing Lot for Lot untuk setiap bahan baku SH-15 pada PT. Latif dapat meminimalkan biaya total persediaan sebesar Rp 60.000,- apabila dibandingkan dengan metode Lot Sizing Part Period Balancing.
\end{abstract}

Kata Kunci: Lot Sizing, MRP, Peramalan dan Persediaan Bahan Baku

\begin{abstract}
PT. Latif is an industry engaged in synthetic rattan, one of the best-selling products is $\mathrm{SH}-15$. The problem in this study is to discuss about raw materials using a system that is made sequentially. Therefore we need an information system that is expected to meet the needs of raw materials can be carried out appropriately and the determination of procurement costs can be determined as optimal as possible through the application of MRP. The research variable in this case is raw material research planning. MRP begins by forecasting the number of requests / production for the future. This forecasting is done using the Moving Average method N = 1, and Single Exponential Smoothing = 0.8 . Then the high values of the SEE, MAD, and MAPE of each method were determined. After selecting one of the best methods, a foundation will be needed to predict the number of demand needs for the next year. Comparison between the minimum lot method minimum cost for Lot of Rp.60,000 and the Balancing Period portion of Rp. 44,733,750. From the results of the calculation of the two lot sizing can be concluded from the application of the Lot Sizing Lot method for Lot for each SH-15
\end{abstract}


raw material at PT. The overall amount that can be agreed upon is Rp. 60,000 agreed upon compared to the Lot Sizing Part Period Balancing method.

Keyword : Lot Sizing, MRP, Forecasting and Inventory of Raw Materials

\section{Pendahuluan}

Perusahaan yang didirikan tentunya disertai dengan harapan bahwa kelak dikemudian hari akan mengalami perkembangan yang pesat. Apapun lingkup usaha dari perusahaan tersebut serta bagaimanapun bentuk dari perusahaan, tidak terkecuali semuanya ingin berkembang. Harapan yang cerah dikemudian hari merupakan salah satu dasar untuk mengambil tindakan-tindakan yang dianggap diperlukan pada saat sekarang. Namun tidak kurang pula adanya kenyataan bahwa dari sekian banyak perusahaan yang telah didirikan tersebut tidak dapat berkembang, sesuai dengan yang diharapkan. Perusahaan-perusahaan semacam ini mempunyai beberapa kesulitan untuk melaksanakan kegiatan operasi dari dalam perusahaannya, sehingga pelaksanaan kegiatan dalam perusahaan yang bersangkutan menjadi terhambat. Hal ini lebih parah lagi dalam perusahaan semacam ini adalah terdapatnya berbagai macam kesulitan dari dalam perusahaan tersebut untuk sekedar mempertahankan kelangsungan hidup dari perusahaan yang bersangkutan.

Dari berbagai macam masalah dan tantangan yang harus dapat diselesaikan didalam perusahaan untuk mempertahankan kelangsungan hidup serta memperkembangkan perusahaan adalah masalah kegiatan produksi dari dalam perusahaan tersebut. PT. Latif adalah sebuah perusahaan manufaktur yamg bergerak dibidang furniture rotan sintetik. Produk yang mereka hasilkan adalah kursi, meja, rak dan beberapa aneka aksesoris perabot ruangan. Perencanaan dan pengendalian yang baik dalam proses produksi diperlukan agar semua proses dapat berjalan dengan lancar sehingga efisiensi dan efektifitas produksi dapat tercapai [1],[2]. Dalam hal proses produksi sangat berkaitan dengan perencaan waktu yang diasumsikan dalam sekali periode produksi. Dengan adanya waktu yang direncanakan, perusahaan diharap mampu memberikan prediksi produksi dalam waktu yang ditetapkan. Proses produksi akan terkendala, jika terjadi kerusakan mesin produksi serta waktu yang diasumsikan menyimpang, maka kegiatan produksi selain tidak berjalan, juga merugikan dalam tahapan order produk yang siap dipasarkan.

Selama ini perusahaan melakukan perencanaan dan pengendalian hanya berdasarkan pada pengalaman-pengalaman sebelumnya, tidak berdasarkan pada metode - metode yang sudah baku. Hal tersebut sering menyebabkan terjadinya kelebihan ataupun kekurangan stok bahan baku yang dapat menyebabkan membengkaknya biaya dan terhambatnya proses produksi untuk memenuhi permintaan konsumen [3]. Terlebih proses produksi yang dijalankan di PT. Latif menggunakan sistem made in order, sehingga ketersediaan stok material sangat berpengaruh terhadap kelancaran proses produksi [4],[5],[6],[7]. Berdasarkan latar belakang di atas terdapat beberapa tujuan dalam penelitian ini yakni mengetahui perencanaan kebutuhan material pada produk furniture di PT. Latif, mengetahui sistem MRP yang paling sesuai untuk diterapkan pada perencanaan persediaan material pada PT. Latif, dan mengetahui peran sistem MRP dalam perencanaan pengadaan bahan baku PT. Latif [8],[9],[10],[11].

\section{Metode Penelitian}

\subsection{Lokasi dan Waktu Penelitian}

Penelitian dilakukan pada PT. Latif Industries International Kediri -Jawa Timur yang merupakan perusahaan manufaktur berskala internasional yang memproduksi beberapa jenis dan merk furniture yang berlokasi di Jalan Kediri-Kertosono Km.13 Desa Minggiran Kecamatan Papar Kabupaten Kediri. Sedangkan penelitian dilakukan selama kurung waktu tertentu hingga terpenuhinya data penelitian. 


\subsection{Variabel Dalam Penelitian}

Definisi operasional dalam perencanaan pengendalian persediaan bahan baku yaitu suatu sistem yang dilakukan oleh manajemen dalam mengatur persediaan bahan baku di perusahaannya yang mempunyai tujuan untuk memperoleh total biaya persediaan yang paling efisien.

Variabel adalah suatu definisi yang diberikan kepada suatu variabel atau konstrak dengan cara memberikan arti atau menspesifikasikan kegiatan ataupun memberikan operasional yang diperlukan untuk mengukur konstrak atau variabel tersebut [12].

Variabel penelitian adalah segala sesuatu yang berbentuk apa saja yang ditetapkan oleh peneliti untuk dipelajari sehingga diperoleh informasi tentang hal tersebut, kemudian ditarik kesimpulanya [13]. Sehingga yang menjadi variabel penelitian dalam hal ini adalah perencanaan dan pengendalian persediaan bahan baku.

Dalam penelitian ini, peneliti menggunakan variabel dan indikator yang dapat dilihat pada tabel sebagai berikut :

Tabel 1 Operasional Variabel dan Indikator Penelitian

\begin{tabular}{|c|c|c|c|}
\hline Variabel & Proses MRP & Metode & Indikator \\
\hline $\begin{array}{l}\text { Material } \\
\text { Requirement } \\
\text { Planning } \\
\text { (MRP) }\end{array}$ & 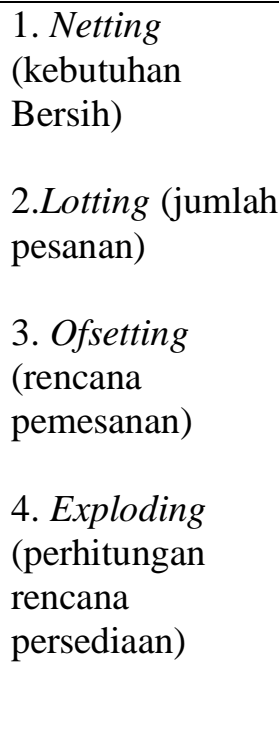 & $\begin{array}{l}\text { 1.Forecasting (peramalan) } \\
\text { Perhitungan menggunakan } \\
\text { bantuan sofware Minitab } \\
14.1 \\
\checkmark \text { Moving Average } \\
\checkmark \text { Exponensial smoothing } \\
\text { 2. Proses perhitungan MRP : } \\
\checkmark \text { Menenukan jadwal induk } \\
\text { produksi (JIP) kebutuhan } \\
\checkmark \text { Menentukan jumlah } \\
\text { bahan baku setiap periode } \\
\checkmark \text { Menentukan pesanan (ukuran lot), } \\
\text { o Lot for lot o Part Periode Balancing }\end{array}$ & $\begin{array}{l}\text { Penerapan } \\
\text { metode MRP } \\
\text { pada PT. Latif } \\
\text { dalam } \\
\text { merencanakan } \\
\text { persediaan } \\
\text { bahan } \\
\text { baku furniture } \\
\text { dapat berjalan } \\
\text { efektif dan } \\
\text { efisien }\end{array}$ \\
\hline
\end{tabular}

\subsection{Sumber Data}

Sumber data berasal dari internal perusahaan. Sedangkan jenis data yang digunakan dalam penelitian ini dibagi menjadi 2 macam yaitu data primer dan data Sekunder. Data tersebut meliputi :

\section{a. Data Primer}

Data primer merupakan data yang secara langsung diperoleh dari sumber data atau objek penelitian dan masih harus diteliti serta memerlukan pengolahan lebih lanjut lagi. Adapun data primer tersebut adalah sebagai berikut :

1) Data permintaan furniture selama 1 tahun.

2) Data Bill Of Material furniture $\mathrm{SH}-15$.

b. Data sekunder

Data sekunder adalah data yang diperoleh dari perusahaan dan data tersebut sudah diolah seperti gambaran umum perusahaan. Data tersebut meliputi :

1) Struktur organisasi perusahaan.

2) Data aktual persediaan bahan baku

3) Biaya pesan, biaya simpan. 
4) Lead time pemesanan bahan baku.

\subsection{Metode Pengumpulan Data}

Untuk dapat memperoleh data dalam penyusunan Tugas Akhir ini, penulis menggunakan beberapa teknik pengumpulan data sebagai berikut :

1. Penelitian Lapangan (Field Risearch)

Dalam pengumpulan data dilapangan penulis menganalisis secara langsung pada obyek yang sedang diteliti dengan maksud untuk mendapatkan data yang primer.

\section{Studi Literatur}

Setelah masalah yang ada dirumuskan dengan baik, maka langkah selanjutnya adalah mencari teori- teori, konsep-konsep yang dapat digunakan sebagai landasan teori bagi penelitian yang dilakukan. Teori-teori tersebut didapatkan dari buku-buku perkuliahan, penelitian terdahulu, jurnal serta literatur-literatur lainnya yang berkaiatan dengan pokok permasalahan yang dihadapi.

\subsection{Populai dan Sampel}

Populasi adalah keseluruhan subjek atau objek yang menjadi pusat perhatian peneliti. Populasi dapat berupa himpunan orang, benda, kejadian, gejala, kasus, waktu dan tempat. Populasi dapat berstatus sebagai objek penelitian jika populasi tersebut sebagai substansi yang diteliti. Populasi penelitian dapat berstatus sebagai sumber informasi. Populasi dalam penelitian ini adalah persediaan bahan baku untuk pembuatan furniture SH-15. Subjek penelitian yang dipilih adalah bahan baku pembuatan furniture untuk produk $\mathrm{SH}-15$.

\subsection{Metode Pengolahan dan Analisis Data}

\subsubsection{Metode analisis data}

\subsubsection{Jadwal produksi induk}

Pembuatan jadwal produksi induk didasarkan pada peramalan permintaan produk. Peramalan permintaan yang digunakan dalam penelitian ini adalah metode statistika deret waktu (time series). Untuk meramalkan permintaan permintaan di masa yang akan datang maka sebelumnya harus melakukan proses sebagai berikut [14]:

1. Buat grafik permintaan versus waktu (permintaan pada sumbu Y dan waktu pada sumbu X).

2. Tentukan metode peramalan deret waktu yang akan digunakan.

3. Hitung ekspetasi kesalahan.

4. Putuskan apakah akan menggunakan metode deret waktu atau menggunakan metode lainnya yang lebih baik.

Proses pembuatan grafik permintaan pada penelitian ini menggunakan software Microsoft Excel. Penentuan metode peramalan deret waktu yang akan digunakan disesuaikan dengan jenis komponen data seperti yang dinyatakan oleh Lindawati (dalam Dwika, 2010:21).

Selanjutnya dilakukan peramalan dan perhitungan ekspetasi kesalahan menggunakan bantuan software Minitab 14.1. Beberapa analisis kesalahan peramalan yang biasanya digunakan adalah [8] :

1) MAD (Mean Absolute Deviation = rata-rata penyimpangan absolut) [15],[16],

$$
M A D=\frac{\sum\left|y 1-y t^{1}\right|}{N}
$$

2) MAPE (Mean Absolute Percent Error = rata-rata persentase kesalahan absolut)[15],[17],[18]

$$
M A P E=\frac{100}{N} \sum\left|\frac{y 1-y t^{1}}{y 1}\right|
$$


3) $\operatorname{MSE}($ Mean Squared Error = rata-rata kuadrat kesalahan)[15],[19]

$$
M S E=\frac{\sum\left(y 1-y t^{1}\right)}{N}
$$

Hasil peramalan dengan MAD, MAPE, dan MSE terkecil dipilih sebagai jadwal produksi induk atau Master Production Schedule (MPS) untuk model Material Requirement Planning (MRP).

\subsubsection{Struktur produk dan daftar kebutuhan bahan (Bill of Material)}

Dalam menentukan apa yang diperlukan untuk sebuah produk, dibutuhkan daftar kebutuhan bahan untuk menunjang proses tersebut. Salah satu cara daftar kebutuhan bahan mendefinisikan sebuah produk adalah dengan cara membuat struktur produk [16], [20]. Proses pembuatan struktur produk ini didasarkan pada produk yang diteliti dan proses produksinya [21],[22],[23].

\subsubsection{Rencana Kebutuhan Bahan (MRP)}

Penghitungan Material Requirement Planning (MRP) dalam penelitian ini dilakukan dengan menggunakan bantuan program software Microsoft Excel, karena jumlah item yang terlihat dalam produksi relatif banyak. Analisis Rencana Kebutuhan bahan (Material Requirement Planning) dalam penelitian ini dilakukan dengan tahapan offsetting, netting, explosion, dan lotting dengan teknik Lot for Lot (LFL) dan Part Period Balancing (PPB) [24],[25],[18]. Selanjutnya membuat tabel Material Requirement Planning untuk setiap teknik lotting [18],[26],[27],[28].

\section{Pembahasan}

\subsection{Analisis Hasil Pengolahan Data}

\subsubsection{Peramalan}

Berdasarkan plot data permintaan masa lalu pada gambar 4.4, dapat dilihat bahwa permintaan tersebut terjadi secara runtut waktu. Permintaan yang memiliki pola runtut waktu dapat menggunakan metode penghalusan (smoothing) peramalan Moving Average dan Single Exponential Smoothing [4].

Berdasarkan perhitungan yang telah dilakukan dengan menggunakan metode Moving Average dan Single Exponential Smoothing, diperoleh bahwa metode yang tepat adalah Moving Average sebab memiliki nilai MAD, MAPE dan MSD paling kecil [29].

Berdasarkan metode Moving Average, peramalan untuk bulan Januari sampai dengan Desember tahun 2017 yaitu sebesar 2650. Agar lebih jelas disajikan tabel sebagai berikut.

Tabel 2 Peramalan Permintaan Furniture SH-15 Bulan Januari 2017 sampai Desember 2017

\begin{tabular}{|l|c|}
\hline Bulan & Order (pcs) \\
\hline Januari & 2650 \\
\hline Februari & 2650 \\
\hline Maret & 2650 \\
\hline April & 2650 \\
\hline Mei & 2650 \\
\hline Juni & 2650 \\
\hline Juli & 2650 \\
\hline Agustus & 2650 \\
\hline September & 2650 \\
\hline Oktober & 2650 \\
\hline November & 2650 \\
\hline Desember & 2650 \\
\hline
\end{tabular}




\subsubsection{Master Production Schedules (MPS)}

MPS (Master Production Schedules) mewakili sebuah rencana untuk pelaksanaan produksi. MPS dibuat berdasarkan hasil forecasting dan pesanan konsumen [16]. Karena produksi di PT. Latif Kediri adalah made in order, maka MPS yang dibuat hanya berdasarkan forecasting saja.

Untuk memudahkan perhitungan dan pelaksanaannya, maka dari MPS tersebut ditampilkan dalam bentuk bulanan (tergantung pemakaian). Dengan mengasumsikan bahwa dalam 1 bulan terdapat permintaan sebesar 2650 pes furniture SH-15.

\subsubsection{Hasil pengolahan data metode Lot Sizing (MRP)}

Penghitungan lot sizing tersebut dilakukan dengan menggunakan bantuan software microsoft excel. Dari hasil penghitungan dengan menggunakan metode Lot for Lot dan Part Periode Balancing, maka langkah selanjutnya adalah membandingkan hasil dari kedua metode tersebut. Tabel 5.3 di bawah ini akan memberikan gambaran secara jelas perbandingan kedua metode tersebut untuk tiap tiap bahan baku.

Tabel 3 Perbandingan Hasil Lot Sizing

\begin{tabular}{|c|c|c|c|}
\hline \multirow[b]{2}{*}{ No } & \multirow[b]{2}{*}{ Item } & \multicolumn{2}{|c|}{ Metode Lot Sizing } \\
\hline & & Lot for Lot & $\begin{array}{c}\text { Part Periode } \\
\text { Balancing }\end{array}$ \\
\hline 1 & Pipa Ø 19 mm & Rp 60.000,- & Rp 44.733.750,- \\
\hline 2 & Pipa Ø 25 mm & Rp 60.000,- & Rp 47.715.000,- \\
\hline 3 & cat / powder & $\operatorname{Rp} 60.000,-$ & $\operatorname{Rp} 372.750,-$ \\
\hline 4 & Paku / Staples & $\operatorname{Rp} 60.000,-$ & $\operatorname{Rp} 3.592 .500,-$ \\
\hline 5 & HDPE & Rp 60.000,- & Rp 4.951.950,- \\
\hline 6 & LDPE & Rp 60.000,- & Rp 1.746.510,-- \\
\hline 7 & Uv mx & Rp 60.000,- & $\operatorname{Rp} 234.420,-$ \\
\hline 8 & Mb Brown 1 & Rp 60.000,- & Rp 53.160,- \\
\hline 9 & Mb Yellow & $\operatorname{Rp} 60.000,-$ & Rp 301.200,- \\
\hline 10 & Mb White & Rp 60.000,- & Rp 18.816,- \\
\hline 11 & Mb Black & Rp 60.000,- & Rp 34.080,- \\
\hline 12 & Regucel & Rp 60.000,- & Rp 29.310,- \\
\hline 13 & $\mathrm{Az}-\mathrm{h}$ & Rp 60.000,- & $\operatorname{Rp} 48.390,-$ \\
\hline 14 & W oil & Rp 60.000,- & $\operatorname{Rp} 24.540,-$ \\
\hline 15 & Mb Brown 2 & $\operatorname{Rp} 60.000,-$ & $\operatorname{Rp} 34.080,-$ \\
\hline 16 & Busa/spon & Rp 60.000,- & $\operatorname{Rp} 372.750,-$ \\
\hline 17 & Kain & Rp 60.000,-- & Rp $1.446 .000,-$ \\
\hline 18 & Resleting & Rp 60.000,- & Rp 778.200,- \\
\hline 19 & Benang & Rp 60.000,-- & $\mathrm{Rp} 1.207 .500,-$ \\
\hline 20 & Kaki kursiCE & Rp 60.000,- & Rp 34.080,- \\
\hline 21 & Kaki kursi SH & Rp 60.000,- & Rp 34.080,- \\
\hline
\end{tabular}

Dari data pada Tabel 3 tersebut, dapat ditentukan jenis metode yang paling optimal untuk tiaptiap bahan baku. Misalnya untuk bahan baku HDPE, dari kedua hasil lot sizing yang ada, metode lot for lot menghasilkan biaya yang paling minimum, yaitu sebesar Rp 60.000,-. Oleh karena itu nantinya dalam penyusunan tabel MRP, jumlah lot untuk pembelian bahan baku produk furniture SH-15 akan digunakan hasil penghitungan dari metode lot for lot. 


\section{Kesimpulan}

Berdasarkan analisis yang telah dilakukan pada bab sebelumnya, penulis menarik kesimpulan bahwa :

1. Selama ini perusahaan melakukan produksi berdasarkan sistem made in order, yaitu mengerjakan produksi furniture apabila ada pemesanan dari konsumen. Karena menggunakan sistem made in order, ketepatan dalam pemenuhan kebutuhan konsumen baik harga, jumlah, maupun waktu yang tepat tersebut menjadi perioritas utama untuk menjaga kelangsungan hidup perusahaan tersebut agar tetap terus berjalan dan berkembang.

2. Perencanaan kebutuhan material yang optimum dapat dilakukan dengan menggunakan metode Material Requirement Planning (MRP). Metode tersebut diawali dengan melakukan peramalan akan jumlah permintaan / produksi untuk waktu yang akan datang. Peramalan ini dilakukan dengan menggunakan metode Moving Average N = 1, dan Single Exponential Smoothing $=0.8$. Lalu ditentukan nilai terkecil dari SEE, MAD, dan MAPE dari masing-masing metode. Setelah terpilih salah satu metode terbaik maka metode tersebut akan dijadikan landasan untuk meramalkan jumlah kebutuhan permintaan selama satu tahun kedepan.

3. Dari hasil analisa dengan menggunakan metode MRP. Dapat disimpulkan bahwa perusahaan dalam melakukan pemesanan dapat menggunakan metode lot for lot untuk pemesanan jumlah besar, karena memiliki biaya yang paling rendah sebesar Rp.60.000,-. Namun jika perusahaan melakukan pemesanan dalam jumlah kecil, perusahaan dapat menggunakan metode Part Periode Balancing sebesar Rp. 18.816,- yang memiliki biaya paling minimum.

\section{Daftar Pustaka}

[1] M. Shin, H. Lee, K. Ryu, Y. Cho, and Y.-J. Son, "A two-phased perishable inventory model for production planning in a food industry," Syst. Ind. Eng., vol. 133, pp. 175-185, 2019.

[2] D. Ivanov, A. Tsipoulanidis, and J. Schönberger, "Production and Material Requirements Planning," in Global Supply Chain and Operations Management: A Decision-Oriented Introduction to the Creation of Value, Cham: Springer International Publishing, 2017, pp. 317343.

[3] Marioandi, "Fungsi Gudang," blogspot.com2, 2017. [Online]. Available: https://marioandi.blogspot.com/2017/09/fungsi-gudang.html. [Accessed: 16-Mar-2020].

[4] L. Miao, D. Cao, J. Li, and W. Guan, "Multi-modal product title compression," Inf. Process. Manag., vol. 57, no. 1, p. 102123, 2020.

[5] T. Chernonog, "Inventory and marketing policy in a supply chain of a perishable product," Int. J. Prod. Econ., Jun. 2019.

[6] M. I. S. Sihombing and S. Sumartini, "Pengaruh Pengendalian Kualitas Bahan Baku dan Pengendalian Kualitas Proses Produksi terhadap Kuantitas Produk Cacat dan Dampaknya pada Biaya Kualitas (Cost of Quality)," J. ILMU Manaj. DAN BISNIS, 2017.

[7] L. F. de Souza Cardoso, F. C. M. Q. Mariano, and E. R. Zorzal, "A survey of industrial augmented reality," Comput. Ind. Eng., vol. 139, no. October 2019, p. 106159, 2020.

[8] N. Y. Astana, "Perencanaan Persediaan Bahan Baku Berdasarkan Metode MRP (Material Requirements Planning) I," J. Ilm. Tek. Sipil, 2007.

[9] K. A. Martha and P. Y. Setiawan, "ANALISIS MATERIAL REQUIREMENT PLANNING PRODUK COCONUT SUGAR PADA KUL-KUL FARM," E-Jurnal Manaj. Univ. Udayana, 2018.

[10] I. B. Kurnia D, Bastuti S, “Analisis Pengendalian Bahan Baku Pada Produk Tas Dengan Menggunakan Metode Material Requirements Planning ( MRP ) Untuk Meminimalkan Biaya Penyimpanan Di Home Industry Amel Collection,” JITMI, 2018. 
[11] Y. Ming, R. Houé, and B. Grabot, "MRP-based negotiation in customer-supplier relationship," IFAC Proc. Vol., vol. 14, no. PART 1, pp. 628-633, 2012.

[12] I. K. Swarjana, "Variabel Penelitian," J. Progr. Stud. Pendidik. Guru Raudhatul Athfal ISSN 2338-2163 - Vol. 05, vol. 05, p. 41, 2018.

[13] A. Heryana, "Kerangka Teori, Kerangka Konsep, Variabel Penelitian, Dan Hipotesis Penelitian (Dalam Penelitian Kuantitatif)," Metodol. Penelit., 2015.

[14] A. Kusumawati and A. D. Setiawan, "Analisis Pengendalian Persediaan Bahan Baku Tempe Menggunakan Material Requirement Planning," Ind. Serv., vol. 3, no. 1, pp. 168-173, 2017.

[15] U. Khair, H. Fahmi, S. Al Hakim, and R. Rahim, "Forecasting Error Calculation with Mean Absolute Deviation and Mean Absolute Percentage Error," in Journal of Physics: Conference Series, 2017.

[16] T. Nadu, "Material Requirement Planning for Automobile Service Plant," Int. J. Innov. Res. Sci. Eng. Technol., vol. 2014, no. 3, 2015.

[17] E. Rimawan, D. S. Saroso, and P. E. Rohmah, "Analysis of Inventory Control with Material Requirement Planning ( MRP ) Method on IT180-55gsm F4 Paper Product at PT . IKPP , TBK," vol. 3, no. 2, pp. 569-581, 2018.

[18] D. Sari and W. Budiawan, "Analisis Penerapan Material Requirement Planning (Mrp) dengan Mempertimbangkan Lot Sizing dalam Pengendalian Persediaan Kebutuhan Bahan Baku Xoly untuk Pembuatan Alkyd 9337 pada PT. Pjc," None, vol. 6, no. 1, 2017.

[19] N. Hasanati, E. Permatasari, N. Nurhasanah, and S. Hidayat, "Implementation of Material Requirement Planning (MRP) on Raw Material Order Planning System for Garment Industry," IOP Conf. Ser. Mater. Sci. Eng., vol. 528, no. 1, pp. 0-8, 2019.

[20] E. Acar et al., "Development of Stitched, Braided and Woven Composite Structures in the ACT Program and at Langley Research Center (1985 to 1997)," J. Aircr., 2011.

[21] S. Feng, H. Zhou, and H. Dong, "Using deep neural network with small dataset to predict material defects," Mater. Des., vol. 162, pp. 300-310, 2019.

[22] D. Cahyono, "Sistem Informasi Standard Bill Of Material Quantity Genset di PT Conductorjasa Suryapersada," J. Inf., vol. 2, no. 2, pp. 1-5, 2017.

[23] B. N. Sari, O. Komarudin, T. N. Padilah, and M. Nurhusaeni, "Bill of Material (Bom) Pada Sistem Inventori Kawasan Berikat Untuk Pelacakan Material Movement," Ilk. J. Ilm., vol. 10, no. 3, pp. 323-330, 2018.

[24] A. Chandradevi and N. B. Puspitasari, "Penerapan Material Requirement Planning (MRP) dengan Mempertimbangkan Lot Sizing dalam Pengendalian Bahan Baku pada PT. Phapros, Tbk.," PERFORMA Media Ilm. Tek. Ind., vol. 15, no. 1, pp. 77-86, 2016.

[25] E. W. Fajriyah, M. F. F. Mu'tamar, and A. Rahman, "Perencanaan Persediaan Bahan Baku Rajungan Menggunakan Metode MRP (Material Requirement Planning) (Studi Kasus : UD. Gerald Unedo)," Rekayasa, vol. 10, no. 1, p. 9, 2018.

[26] M. Q. Mahfudhon, A. Wahyudi, and E. Widajanti, “Analisis Pengendalian Persediaan Bahan Baku Dengan Menggunakan Metode Material Requirement Planningpada PT Atmi Duta Engineering," J. Ekon. dan Kewirausahaan, vol. 18, pp. 83-89, 2018.

[27] Y. E. Torunoglu, H. Kirli Akin, and N. Guler, "Material Requirement Planning in a Briquette Factory," Int. Adv. Res. Eng. J., vol. 01, no. 01, pp. 21-25, 2017. 
[28] P. A. Irawan and A. Syaicu, "PENGENDALIAN PERSEDIAAN BAHAN BAKU DENGAN METODE MATERIAL REQUIREMENT PLANNING (MRP) PADA PT. SEMEN INDONESIA (PERSERO), Tbk.,” J. Knowl. Ind. Eng., vol. 4, no. 1, pp. 15-22, 2017.

[29] S. Wardah and I. Iskandar, "ANALISIS PERAMALAN PENJUALAN PRODUK KERIPIK PISANG KEMASAN BUNGKUS (Studi Kasus : Home Industry Arwana Food Tembilahan)," J@ti Undip J. Tek. Ind., vol. 11, no. 3, p. 135, 2017. 